\title{
Variable Responsive Wettability Films via Electrospinning Induced by Solvents
}

\author{
Nü Wang, Fengyun Guo, Jing Wu, Yong Zhao, and Lei Jiang \\ Key Laboratory of Bioinspired Smart Interfacial Science and Technology of Ministry of Education, Beijing Key Laboratory of Bioinspired \\ Energy Materials and Devices, School of Chemistry and Environment, Beihang University, Beijing 100191, China
}

Correspondence should be addressed to Nü Wang; wangn@buaa.edu.cn and Yong Zhao; zhaoyong@buaa.edu.cn

Received 2 January 2014; Accepted 22 January 2014; Published 2 March 2014

Academic Editor: Yongping Hou

Copyright (C) 2014 Nü Wang et al. This is an open access article distributed under the Creative Commons Attribution License, which permits unrestricted use, distribution, and reproduction in any medium, provided the original work is properly cited.

Three kinds of interesting distinct wettability films are fabricated by a facile electrospinning technique. The films are composites of poly(N-isopropylacrylamide) and polystyrene but different precursor solvents. By taking advantage of the conformational changes of poly( $\mathrm{N}$-isopropylacrylamide) chains and polystyrene chains in different solvents, the films exhibit responsive wettability variation to temperature.

\section{Introduction}

Smart interfacial materials with special wettability have attracted considerable attention in recent years due to their importance for both fundamental research and practical applications [1-4]. Fruitful achievements have been proposed in many areas, for example, superhydrophobic surfaces used for self-cleaning and low-adhesion $[5,6]$ and superhydrophilic surfaces used for antifouling and biomedical devices [7]. Furthermore, special wettability surfaces that can respond to external environment stimuli (e.g., temperature, light, $\mathrm{pH}$, electrical field, solvent, and magnetic field) [813] have been reported through various methods, such as sol-gel method, the plasma method, template method, electrospinning method, surface-initiated atom-transfer radical polymerization, hydrothermal approach, self-assembled monolayers, electrochemical deposition, and layer-by-layer technique [14-20]. Nevertheless, most of the smart surfaces fabricated are still limited to laboratory. With the unceasing in-depth exploration and consideration of these functional materials, it is of particular important to develop a facile method and manufacture on large scale.

Electrospinning has been widely recognized as an efficient and promising technique of preparing polymer micro/nanofibers in recent years [21, 22]. Researchers found that the structure and property of electrospinning fibers can be influenced by many factors, including polymers' solubility, molecular weight, solvent, the solution properties (e.g., viscosity, elasticity, conductivity, and surface tension), and ambient parameters (e.g., temperature, humidity, and air velocity) [23-27], while it is well known that the solvent is an important factor affecting the morphology of fibers. Examples include that Megelski et al. investigated the influence of different polymer/solvent systems on the fiber micro-/nanoporous surface morphology [24]. As far as mentioned above, many researches have been interested in the influence of polymer/solvent on the fiber surface morphology in the process of electrospinning; few people pay attention to the property of the fiber surfaces. In addition, heterogeneous materials are attractive because they may endow new function different to the intrinsic properties of two original materials. Herein, we designed and fabricated poly(N-isopropylacrylamide) (PNIPAAm)/polystyrene (PS) composite films with various wettability via electrospinning by using different precursor solvents. By taking advantages of distinct conformational changes of PNIPAAm chains and PS chains in different solvents, variable responsive wettability films have been successfully realized. The water contact angle (CA) of the PNIPAAm/PS composite films with N,Ndimethylformamide (DMF) or dichloroethene $\left(\mathrm{CH}_{2} \mathrm{Cl}_{2}\right)$ precursor solution is completely different. The as-prepared PNIPAAm/PS composite film which is formed from DMF 


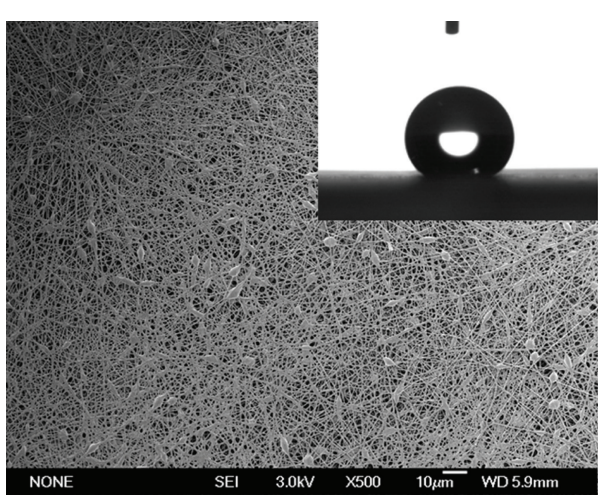

(a)

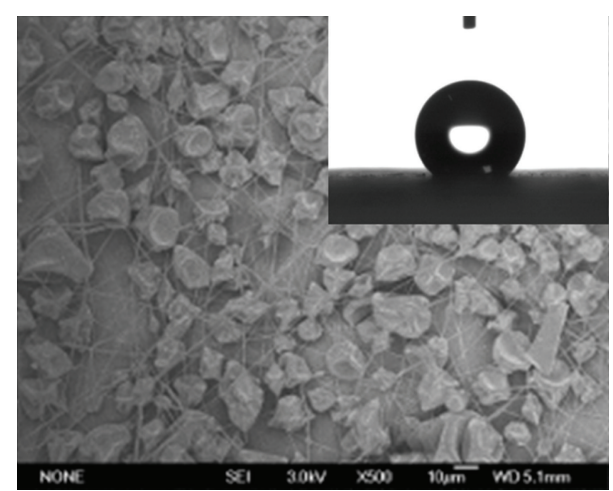

(b)

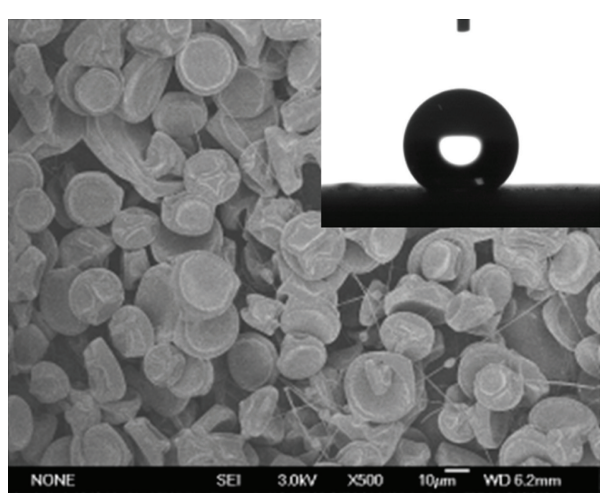

(c)

FIGURE 1: Typical SEM images of the PS films prepared by electrospinning. (a), (b), and (c) correspond to films I, II, and III which were fabricated from a $10 \mathrm{wt} \%$ solution of PS in DMF, $\mathrm{CH}_{2} \mathrm{Cl}_{2}$, and THF, respectively. The insets are photographs of water-droplet shape on the films I, II, and III, respectively.

precursor solution showed superhydrophilicity both before and after increasing temperature. Inversely, the as-prepared PNIPAAm/PS composite film which is formed from $\mathrm{CH}_{2} \mathrm{Cl}_{2}$ precursor solution showed superhydrophobicity both before and after increasing temperature. Interestingly, in a proper proportion of PNIPAAm and PS, the water CA of the composite films in which the solvent is tetrahydrofuran (THF) in precursor solution could switch between superhydrophobic and superhydrophilic when changing the temperature. Distinct conformation of PNIPAAm chains and PS chains in different precursor solvents results in various wettability via electrospinning. It is important for the transformation of polymeric precursor solution into fibers during the process of electrospinning.

\section{Experimental}

2.1. Preparation of Polystyrene (PS) Films. PS (homopolymer, $M_{w}=230,000$, Aldrich) was dissolved in solvents by stirring for $4 \mathrm{~h}$ to form $10 \mathrm{wt} \%$ transparent solution. The solvents are DMF, $\mathrm{CH}_{2} \mathrm{Cl}_{2}$, and THF (A.R.), respectively, which were purchased from Beijing Yili Fine Chemical Co., Ltd. About $2 \mathrm{~mL}$ of the precursor solution was placed in a $5 \mathrm{~mL}$ syringe equipped with a blunt metal needle of $0.7 \mathrm{~mm}$ inner diameter. The solution feed rate is about $0.5 \mathrm{~mL} / \mathrm{h}$. The needle was connected to a high voltage generator, and a grounded metallic plate covered with a sheet of aluminum foil served as a collecting substrate. The distance between the needle tip and collector was $10-20 \mathrm{~cm}$, and the voltage was set at $15-20 \mathrm{kV}$.

2.2. Preparation of PNIPAAm/PS Composite Films. Preparation of PNIPAAm/PS composite films was similar to that of PS film. The PNIPAAm (poly(N-isopropylacrylamide), Mn = 20000-25000, Aldrich) and PS were mixed and dissolved in DMF, $\mathrm{CH}_{2} \mathrm{Cl}_{2}$, and THF, respectively, and stirred for $4 \mathrm{~h}$. The proportion of PNIPAAm, PS, and solvent is 2:10:90 (PNIPAAm/PS/solvent).

2.3. Characterization. The morphology and structure features of the composite films were characterized by field emission scanning electron microscopy (FE-SEM) (JEOL JSM-6700F) at $3.0 \mathrm{kV}$. Contact angle was measured on a dataphysics OCA20 contact angle system at ambient temperature. The temperature was controlled by a superthermostat (Julabo F25, Germany). Water droplet (about $2 \mu \mathrm{L}$ ) was dropped carefully onto the samples. The average CA values were obtained by measuring five different positions of the same sample.

\section{Results and Discussion}

The PS films were prepared by electrospinning with a variety of PS/solvent solutions. Firstly, we prepared film I from 


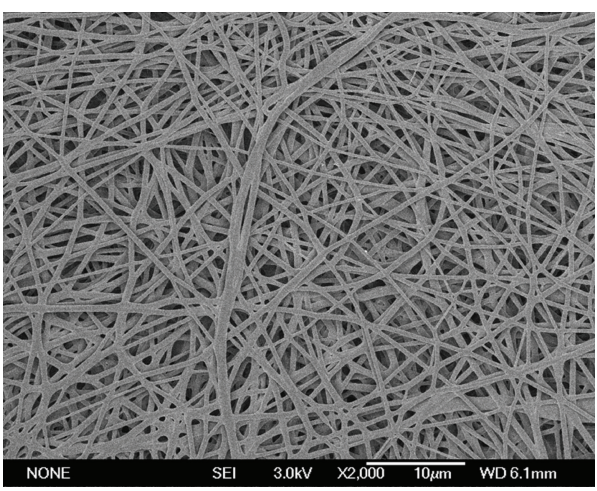

(a)

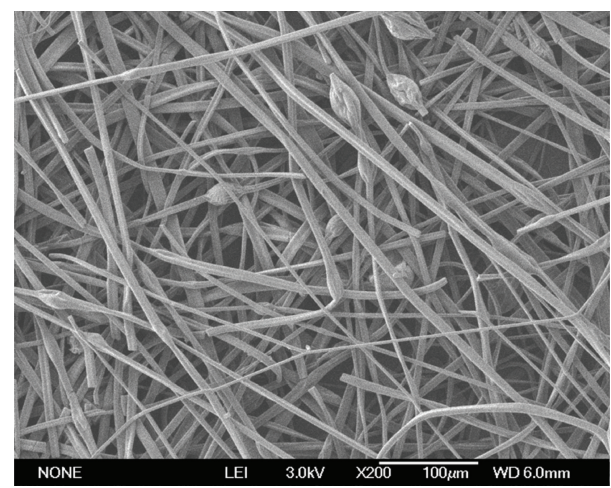

(b)

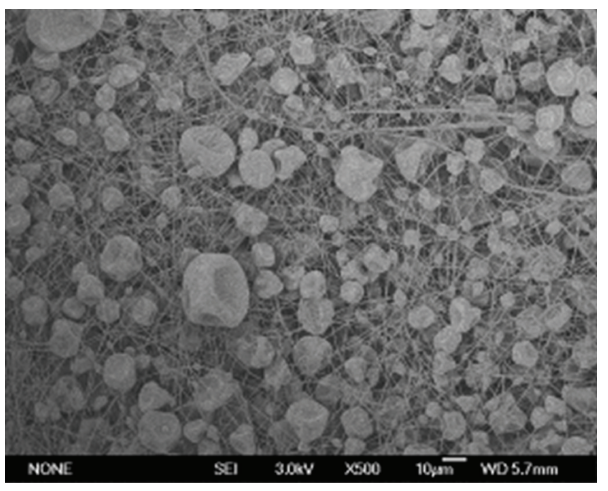

(c)

FIGURE 2: Typical SEM images of PNIPAAm/PS composite films which were fabricated from PNIPAAm/PS/solvents (2:10:90 w/w/w). (a), (b), and (c) correspond to films IV, V, and VI in which the solvent of the precursor solution is $\mathrm{DMF}, \mathrm{CH}_{2} \mathrm{Cl}_{2}$, and THF, respectively.

$10 \mathrm{wt} \%$ PS/DMF solution by electrospinning. The typical filed emission scanning electron microscopy (FE-SEM) image of film I is shown in Figure 1(a). The numerous nanofibers with spindle beads are randomly oriented on the substrate which displays a network structure. Then, we investigated the wetting properties of film I. Film I is hydrophobic with a water CA of $140 \pm 4^{\circ}$ (inset of Figure 1(a)) which is much higher than the plat PS film owing to the rough structure of the as-prepared PS film. This result is corresponding to our previous work [18]. Afterwards, films II and III were fabricated from a $10 \mathrm{wt} \%$ solution of PS in $\mathrm{CH}_{2} \mathrm{Cl}_{2}$ and THF by the similar electrospinning process. Figure $1(\mathrm{~b})$ shows the SEM image of film II which exhibits hierarchical structure with nanofibers and microparticles over the whole substrate. Figure 1(c) shows the SEM image of film III which displays numerous microparticles and a few nanofibers. We measured the wettability of the films with water CA of $144 \pm 4^{\circ}$ and $144 \pm 3^{\circ}$. These results show that the as-prepared electrospun PS films are all hydrophobic because of the rough surface and hierarchical structure. The minor difference in surface structure is due to the influence viscosity and volatility with polymer in different solvents. Also, it will not affect the intrinsic hydrophobic-hydrophilic properties of original materials. Therefore, in order to study the facility we set the same weight proportion of the polymeric precursor solution during the experiment below.
Then, PNIPAAm/PS/solvent solution $(2: 10: 90 \mathrm{w} / \mathrm{w} / \mathrm{w})$ was used to fabricate composite films IV, $\mathrm{V}$, and VI in which the solvents are DMF, $\mathrm{CH}_{2} \mathrm{Cl}_{2}$, and THF, respectively. Figures 2(a), 2(b), and 2(c) show the typical SEM images of films IV, V, and VI. The morphology of the films is not completely identical with the same polymer composition. Concretely, the nanofibers are randomly oriented on the surface of film IV which has a network structure like a spider's web. Compared with the surface of film I, the spindle beads are instead of the numerous uniform nanofibers. It can be easily understood by the addition of PNIPAAm leading to the increase of the viscosity $[19,28]$. The surface of film V (Figure 2(b)) is almost covered with nanofibers except for a few spindle beads. The microparticles in film II surface almost disappear in the surface of film $\mathrm{V}$ when adding PNIPAAm. Figure 2(c) is the SEM image of film VI showing numerous microspheres and nanofibers distributed densely over the surface. It is obvious that the amount of nanofibers increases compared with the SEM image of film III without PNIPAAm. Films IV, V, and VI are prepared with the same polymer composition by electrospinning from different PNIPAAm/PS/solvent precursor solutions. These SEM results show that the surface morphology is not completely uniform with the same polymer composition. The amount of the microspheres and nanofibers is distinct mainly by the reason of the viscosity of precursor solution with different 


\section{】}
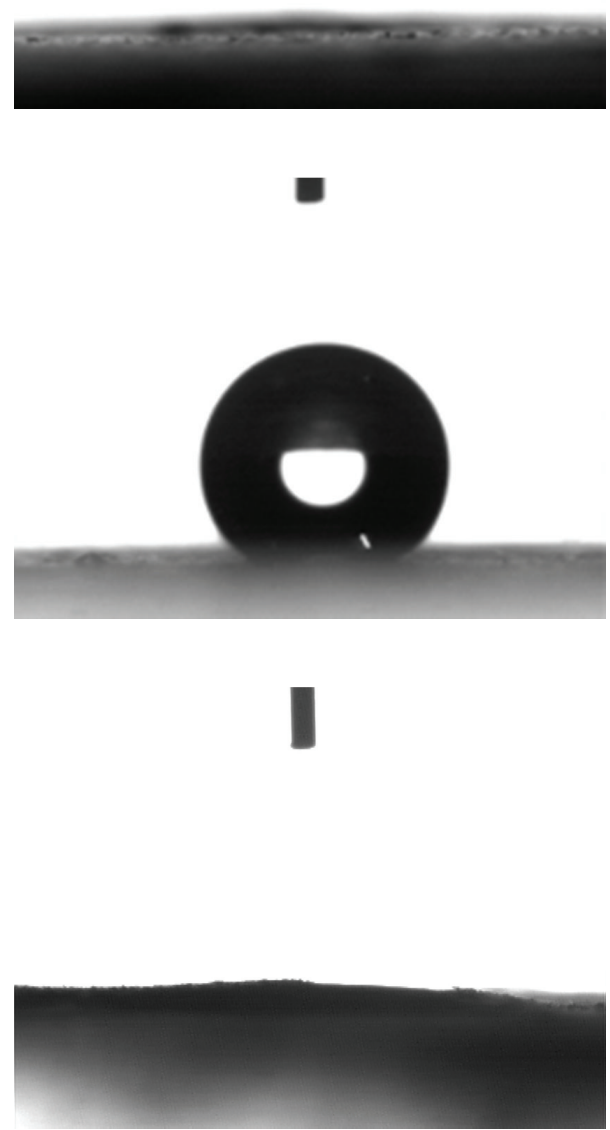

$20^{\circ} \mathrm{C}$

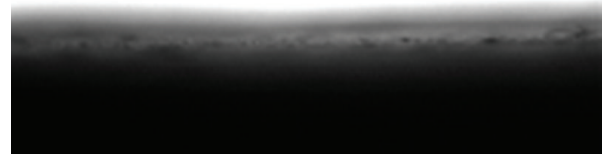

(a)

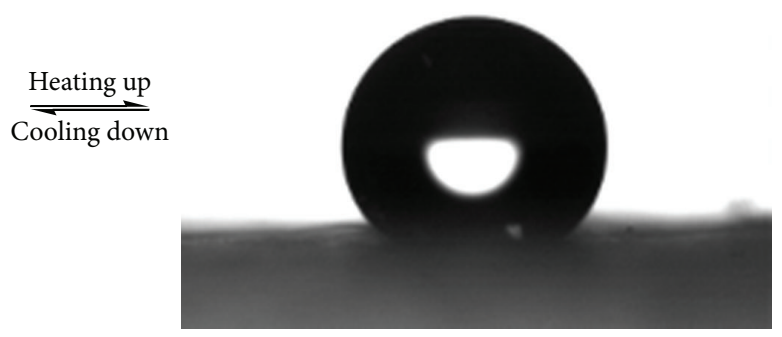

(b)

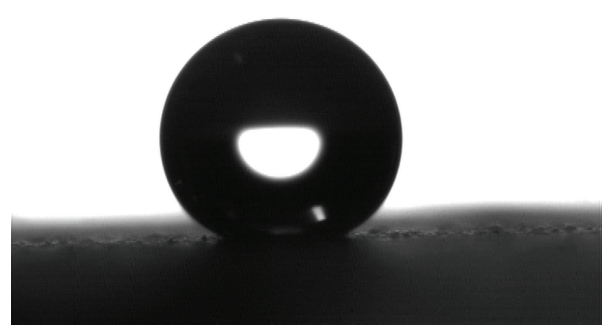

$50^{\circ} \mathrm{C}$

(c)

FIGURE 3: Photographs of water-droplet shape on the PNIPAAm/PS composite films at $20^{\circ} \mathrm{C}$ and $50^{\circ} \mathrm{C}$. (a), (b), and (c) correspond to films $\mathrm{IV}, \mathrm{V}$, and VI in which the solvent of precursor solution is DMF, $\mathrm{CH}_{2} \mathrm{Cl}_{2}$, and THF, respectively. The wettability of PNIPAAm/PS composite films prepared from different precursor solutions is completely distinct when increasing the temperature. The wettability of the PNIPAAm/PS films is both superhydrophilic and superhydrophobic and switches from superhydrophilic to superhydrophobic according to the change in the temperature when the solvents are DMF, $\mathrm{CH}_{2} \mathrm{Cl}_{2}$, and THF, respectively.

solvents and evaporation of the solution droplets during electrospinning process [23-25].

Next, the wetting properties of films IV, V, and VI were investigated. At $20^{\circ} \mathrm{C}$, the water $\mathrm{CA}$ of the films IV, V, and VI is about $0^{\circ}, 133 \pm 3^{\circ}$, and $6 \pm 5^{\circ}$, respectively (Figure 3). Then, the water CA is $0^{\circ}, 142 \pm 5^{\circ}$, and $152 \pm$ $3^{\circ}$, respectively, when the temperature is changed to $50^{\circ} \mathrm{C}$ (Figure 3). Surprisingly, the change of the water CA along with increasing the temperature is completely distinct. The as-prepared film IV, which was added to PNIPAAm in PS/DMF solution, is superhydrophilic according to heating up the surface. Differently, the surface of film $\mathrm{V}$ from PNIPAAm/PS/CH $\mathrm{Cl}_{2}$ precursor is hydrophobic along with the temperature alteration. While the water CA of the film VI from PNIPAAm/PS/THF precursor switched from $6 \pm 5^{\circ}$ to $152 \pm 3^{\circ}$, the temperature changed from $20^{\circ} \mathrm{C}$ to $50^{\circ} \mathrm{C}$.

It is well known that PNIPAAm is a thermoresponsive polymer which has fabricated many thermoresponsive materials by some methods $[19,29,30]$. The mechanism of the stimuli-responsive is explained by the competition between intermolecular and intramolecular hydrogen bonding below and above the lower critical solution temperature (LCST) of 


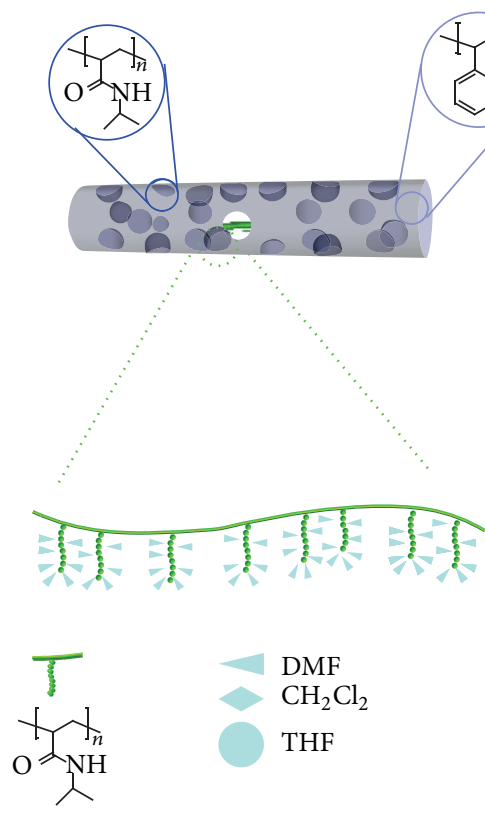

(a)
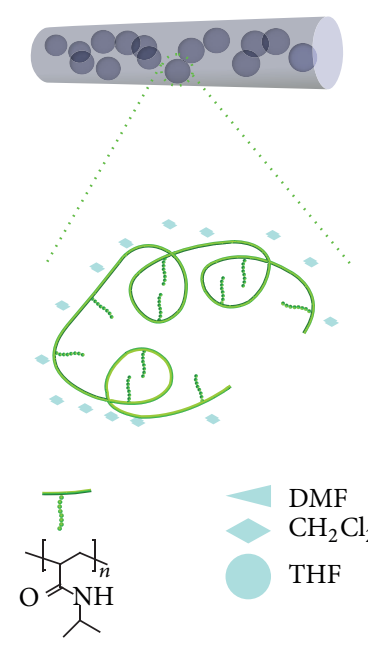

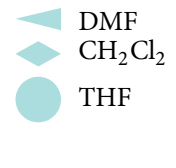

(b)
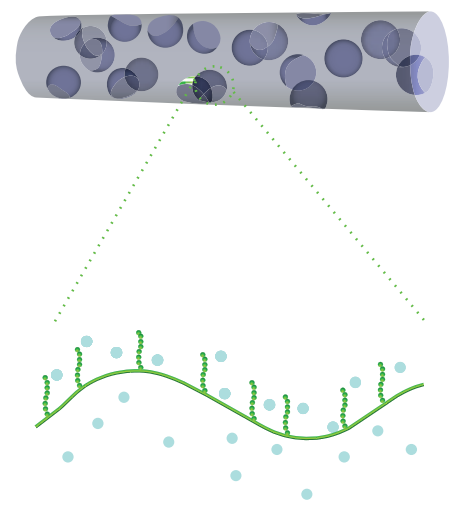

ר

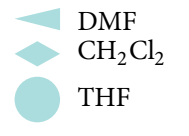

(c)

Figure 4: The diagram of mechanism of the various wetting properties of the as-prepared electrospun films. (a), (b), and (c) represent films $\mathrm{IV}, \mathrm{V}$, and VI in which the solvent of precursor solution is DMF, $\mathrm{CH}_{2} \mathrm{Cl}_{2}$, and THF, respectively. PS mainly formed the fabric structures of the composited films, while the spheres which represent PNIPAAm are distributed differently in composite films IV, V, and VI. The chain diagram represents the idealized conformation between the PNIPAAm chain and solvent molecules in precursor solutions. The polar solvent DMF is likely to form intermolecular hydrogen bonding with PNIPAAm chain. Inversely, the PNIPAAm chain forms easily intramolecular hydrogen bonding when the nonpolar solvent $\mathrm{CH}_{2} \mathrm{Cl}_{2}$ is used. There is not evident hydrogen bonding interaction in the PNIPAAm/PS/THF precursor solution.

about 32 to $33^{\circ}$ [31-33]. The fantastic wettability alteration of PNIPAAm/PS surface has been studied in our previous work and has been explained by the combination of the individual properties of PS and PNIPAAm with the appropriate surface roughness of the film [19]. The PNIPAAm/PS surface exhibits reversible superhydrophilicity and superhydrophobicity by changing the temperature due to freely swell and shrink of the PNIPAAm chains. However, the further results above give us a new assumption that the solvent plays a significant role in the transformation from precursor solution into microspheres/nanofibers through the process of electrospinning.

Figure 4 outlines the proposed mechanism of various wetting property of the as-prepared electrospun films. The fabric structure of the film is mainly made from PS as a result of the majority proportion of precursor solution. While the spheres which represent PNIPAAm are distributed distinctly in various films IV, V and VI, the chain diagram represents the idealized conformation between the PNIPAAm chain and solvent molecules in precursor solutions. As shown in Figure 4(a), DMF is a kind of familiar polar solvent and the value of polarity is 6.4. So in the mixture solution of PNIPAAm, PS, and DMF, the polar $\mathrm{C}=\mathrm{O}$ and $\mathrm{N}-\mathrm{H}$ groups in the PNIPAAm chain interact easily with the DMF molecules to form intermolecular hydrogen bonding. At the same time, the nonpolar $\mathrm{C}-\mathrm{H}$ group in the PNIPAAm and PS tend to intertwist together. Then, in the transformation from polymer precursor solution to fibers with rapid solvent evaporation during electrospinning, the PNIPAAm chain is easily distributed on the surface of the fibers with the polar $\mathrm{C}=\mathrm{O}$ and $\mathrm{N}-\mathrm{H}$ groups barely. Although there are hydrophobic $\mathrm{C}-\mathrm{H}$ groups of PS molecules surrounding the PNIPAAm molecules, the water drops can still move across the PS molecules and interact with $\mathrm{C}=\mathrm{O}$ and $\mathrm{N}-\mathrm{H}$ groups to form intermolecular hydrogen bonding. Therefore, the as-prepared film IV exhibits superhydrophilicity with the water $\mathrm{CA}$ of $0^{\circ}$ at $20^{\circ} \mathrm{C}$. Then, when the temperature is changed to $50^{\circ} \mathrm{C}$, the PNIPAAm chain cannot go around freely which results in the $\mathrm{C}=\mathrm{O}$ and $\mathrm{N}-\mathrm{H}$ groups still exhibiting the surface of the film. Consequently, the film IV is still superhydrophilic with the water CA of $0^{\circ}$ when heating up the surface. Surprisingly, the wettability of film $\mathrm{V}$ from PNIPAAm/PS/ $\mathrm{CH}_{2} \mathrm{Cl}_{2}$ precursor solution is completely different according to heating up the surface. The asprepared film $\mathrm{V}$ is superhydrophobic both before and after increasing the temperature. It is well known that $\mathrm{CH}_{2} \mathrm{Cl}_{2}$ is a kind of nonpolar solvent and the value of polarity is 3.4. Both the $\mathrm{C}-\mathrm{H}$ groups in PNIPAAm and PS will interact with $\mathrm{CH}_{2} \mathrm{Cl}_{2}$ molecular easily in the dissolution process (Figure 4(b)). Hence, the PNIPAAm chain is apt to shrink to form intramolecular hydrogen bonding between the $\mathrm{C}=\mathrm{O}$ and $\mathrm{N}-\mathrm{H}$ groups. After the process of electrospinning with rapid solvent evaporation, most of the fibers surface is occupied by hydrophobic $\mathrm{C}-\mathrm{H}$ groups which accords with the water $\mathrm{CA}$ of $133 \pm 3^{\circ}$. When the temperature is raised above the LCST, the PNIPAAm chain more easily shrinks to form of a compact and collapsed conformation. Thus, the film $\mathrm{V}$ shows hydrophobicity with the water CA of $142 \pm 5^{\circ}$ at high temperature. Besides, the wettability of 
film VI can be switched between superhydrophilicity and superhydrophobicity when changing the temperature. The polarity value of THF is 4.2 which is between DMF and $\mathrm{CH}_{2} \mathrm{Cl}_{2}$ and results in the fact that the PNIPAAm chain could distribute more freely in the PNIPAAm/PS/THF precursor solution (Figure 4(c)). Noticeably, the PNIPAAm chain could still swell and shrink freely on the surface of as-prepared film VI. So the wettability of film VI could be explained by the competition between intermolecular and intramolecular hydrogen bonding in PNIPAAm chain according to changing the temperature which have been studied in detail in our previous work [19].

Therefore, solvents play an extraordinary important role in the transformation from precursor polymer solutions to fibers which induce different physicochemical properties of the surface. In this work, the polar solvent DMF is likely to form intermolecular hydrogen bonding with PNIPAAm chain in precursor solution. The $\mathrm{C}=\mathrm{O}$ and $\mathrm{N}-\mathrm{H}$ groups are easily bared on the surface of the film. So the film IV is superhydrophilic both before and after increasing the temperature. Inversely, the PNIPAAm chain seems more favorable to form intramolecular hydrogen bonding when nonpolar solvent $\mathrm{CH}_{2} \mathrm{Cl}_{2}$ is used. And film $\mathrm{V}$ is hydrophobic when changing the temperature because most of the surface is occupied by C$\mathrm{H}$ groups. The polarity of THF is between DMF and $\mathrm{CH}_{2} \mathrm{Cl}_{2}$; thus, there is no evident hydrogen bonding interaction in the PNIPAAm/PS/THF solution (Figure 4(c)). The PNIPAAm molecular could freely extend and shrink before and after increasing the temperature. The film VI could switch between superhydrophilicity and superhydrophobicity when the temperature is changed from $20^{\circ} \mathrm{C}$ to $50^{\circ} \mathrm{C}$.

\section{Conclusion}

Variable responsive wettability films were fabricated by electrospinning by the result of solvents induced distinct distribution of hydrophilic groups and hydrophobic groups. Three kinds of PNIPAAm/PS films with the same polymer composition present extremely different wettability performance. The wettability of the PNIPAAm/PS films is both superhydrophilic and superhydrophobic and switches from superhydrophilic to superhydrophobic according to change in temperature when the precursor solvents are DMF, $\mathrm{CH}_{2} \mathrm{Cl}_{2}$, and THF, respectively. It could be explained by the competition between intermolecular hydrogen bonding and intramolecular hydrogen bonding in solutions with different solvents. It is the first example to fabricate composite films with same polymer composition but different properties by electrospinning. It gives us an inspiration that new functional and structure materials could be created with proper substance and solvent. It is quite important for the electrospinning research about the solvent induced factors and lays a foundation for the further application of electrospinning.

\section{Conflict of Interests}

The authors declare that there is no conflict of interests regarding the publication of this paper.

\section{Acknowledgments}

The authors acknowledge the Natural Science Foundation of China (21374001, 21222309, 21134003, and 21071148), 973 Program (2012CB933200, 2010CB934700, and 2009CB930404), 863 Program (2012AA030305), and Program for New Century Excellent Talents in University of China for continuous financial support.

\section{References}

[1] X. Yao, Y. Song, and L. Jiang, "Applications of bio-inspired special wettable surfaces," Advanced Materials, vol. 23, no. 6, pp. 719-734, 2011.

[2] D. Quéré, "Wetting and roughness," Annual Review of Materials Research, vol. 38, no. 1, pp. 71-99, 2008.

[3] F. Xia, Y. Zhu, L. Feng, and L. Jiang, "Smart responsive surfaces switching reversibly between super-hydrophobicity and superhydrophilicity," Soft Matter, vol. 5, no. 2, pp. 275-281, 2009.

[4] K. Liu and L. Jiang, "Metallic surfaces with special wettability," Nanoscale, vol. 3, no. 3, pp. 825-838, 2011.

[5] X.-M. Li, D. Reinhoudt, and M. Crego-Calama, "What do we need for a superhydrophobic surface? A review on the recent progress in the preparation of superhydrophobic surfaces," Chemical Society Reviews, vol. 36, no. 8, pp. 1350-1368, 2007.

[6] P. Roach, N. J. Shirtcliffe, and M. I. Newton, "Progess in superhydrophobic surface development," Soft Matter, vol. 4, no. 2, p. 224, 2008.

[7] J. Drelich, E. Chibowski, D. D. Meng, and K. Terpilowski, "Hydrophilic and superhydrophilic surfaces and materials," Soft Matter, vol. 7, no. 21, pp. 9804-9828, 2011.

[8] T. Onda, S. Shibuichi, N. Satoh, and K. Tsujii, "Super-waterrepellent fractal surfaces," Langmuir, vol. 12, no. 9, pp. 2125-2127, 1996.

[9] W. Chen, A. Y. Fadeev, M. C. Hsieh, D. Öner, J. Youngblood, and T. J. McCarthy, "Ultrahydrophobic and ultralyophobic surfaces: some comments and examples," Langmuir, vol. 15, no. 10, pp. 3395-3399, 1999.

[10] J. Bico, C. Tordeux, and D. Quéré, "Rough wetting," Europhysics Letters, vol. 55, no. 2, pp. 214-220, 2001.

[11] X. Zhang, F. Shi, J. Niu, Y. Jiang, and Z. Wang, "Superhydrophobic surfaces: from structural control to functional application," Journal of Materials Chemistry, vol. 18, no. 6, pp. 621-633, 2008.

[12] H. Y. Erbil, A. L. Demirel, Y. Avci, and O. Mert, "Transformation of a simple plastic into a superhydrophobic surface," Science, vol. 299, no. 5611, pp. 1377-1380, 2003.

[13] J. Wu, N. Wang, H. Zhang et al., "Acrylic acid grafted porous polycarbonate membrane with smart hydrostatic pressure response to $\mathrm{pH}$, Journal of Materials Chemistry A, vol. 1, no. 15, pp. 4642-4646, 2013.

[14] S. Minko, M. Müller, M. Motornov, M. Nitschke, K. Grundke, and M. Stamm, "Two-level structured self-adaptive surfaces with reversibly tunable properties," Journal of the American Chemical Society, vol. 125, no. 13, pp. 3896-3900, 2003.

[15] N. J. Shirtcliffe, G. McHale, M. I. Newton, C. C. Perry, and P. Roach, "Porous materials show superhydrophobic to superhydrophilic switching," Chemical Communications, no. 25, pp. 3135-3137, 2005.

[16] N. L. Abbott, C. B. Gorman, and G. M. Whitesides, "Active control of wetting using applied electrical potentials and selfassembled monolayers," Langmuir, vol. 11, no. 1, pp. 16-18, 1995. 
[17] L. Xu, W. Chen, A. Mulchandani, and Y. Yan, "Reversible conversion of conducting polymer films from superhydrophobic to superhydrophilic," Angewandte Chemie, vol. 44, no. 37, pp. 6009-6012, 2005.

[18] L. Jiang, Y. Zhao, and J. Zhai, "A lotus-leaf-like superhydrophobic surface: a porous microsphere/nanofiber composite film prepared by electrohydrodynamics," Angewandte Chemie, vol. 43, no. 33, pp. 4338-4341, 2004.

[19] N. Wang, Y. Zhao, and L. Jiang, "Low-cost, thermoresponsive wettability of surfaces: poly( $\mathrm{N}$ - isopropylacrylamide)/polystyrene composite films prepared by electrospinning," Macromolecular Rapid Communications, vol. 29, no. 6, pp. 485489, 2008.

[20] X. Lu, J. Peng, B. Li, C. Zhang, and Y. Han, "A polymer composite film with reversible responsive behaviors," Macromolecular Rapid Communications, vol. 27, no. 2, pp. 136-141, 2006.

[21] D. Li and Y. Xia, "Electrospinning of nanofibers: reinventing the wheel?” Advanced Materials, vol. 16, no. 14, pp. 1151-1170, 2004.

[22] X. Lu, C. Wang, and Y. Wei, "One-dimensional composite nanomaterials: synthesis by electrospinning and their applications," Small, vol. 5, no. 21, pp. 2349-2370, 2009.

[23] Z.-M. Huang, Y.-Z. Zhang, M. Kotaki, and S. Ramakrishna, "A review on polymer nanofibers by electrospinning and their applications in nanocomposites," Composites Science and Technology, vol. 63, no. 15, pp. 2223-2253, 2003.

[24] S. Megelski, J. S. Stephens, D. Bruce Chase, and J. F. Rabolt, "Micro- and nanostructured surface morphology on electrospun polymer fibers," Macromolecules, vol. 35, no. 22, pp. 84568466, 2002.

[25] K. H. Lee, H. Y. Kim, M. S. Khil, Y. M. Ra, and D. R. Lee, "Characterization of nano-structured poly( $\varepsilon$-caprolactone) nonwoven mats via electrospinning," Polymer, vol. 44, no. 4, pp. 1287-1294, 2003.

[26] L. Moroni, R. Licht, J. de Boer, J. R. de Wijn, and C. A. van Blitterswijk, "Fiber diameter and texture of electrospun PEOT/PBT scaffolds influence human mesenchymal stem cell proliferation and morphology, and the release of incorporated compounds," Biomaterials, vol. 27, no. 28, pp. 4911-4922, 2006.

[27] J. Doshi and D. H. Reneker, "Electrospinning process and applications of electrospun fibers," Journal of Electrostatics, vol. 35, no. 2-3, pp. 151-160, 1995.

[28] H. Fong, I. Chun, and D. H. Reneker, "Beaded nanofibers formed during electrospinning," Polymer, vol. 40, no. 16, pp. 4585-4592, 1999.

[29] T. Sun, G. Wang, L. Feng et al., "Reversible Switching between Superhydrophilicity and Superhydrophobicity," Angewandte Chemie, vol. 43, no. 3, pp. 357-360, 2004.

[30] L. Chen, M. Liu, H. Bai et al., "Antiplatelet and thermally responsive poly(N-isopropylacrylamide) surface with nanoscale topography," Journal of the American Chemical Society, vol. 131, no. 30, pp. 10467-10472, 2009.

[31] Y. G. Takei, T. Aoki, K. Sanui, N. Ogata, Y. Sakurai, and T. Okano, "Dynamic contact angle measurement of temperatureresponsive surface properties for poly( $\mathrm{N}$-isopropylacrylamide $)$ grafted surfaces," Macromolecules, vol. 27, no. 21, pp. 6163-6166, 1994.

[32] T. Yakushiji, K. Sakai, A. Kikuchi, T. Aoyagi, Y. Sakurai, and T. Okano, "Graft architectural effects on thermoresponsive wettability changes of poly( $\mathrm{N}$-isopropylacrylamide)-modified surfaces," Langmuir, vol. 14, no. 16, pp. 4657-4662, 1998.
[33] L. Liang, P. C. Rieke, J. Liu et al., "Surfaces with reversible hydrophilic/hydrophobic characteristics on cross-linked poly(N-isopropylacrylamide) hydrogels," Langmuir, vol. 16, no. 21, pp. 8016-8023, 2000. 

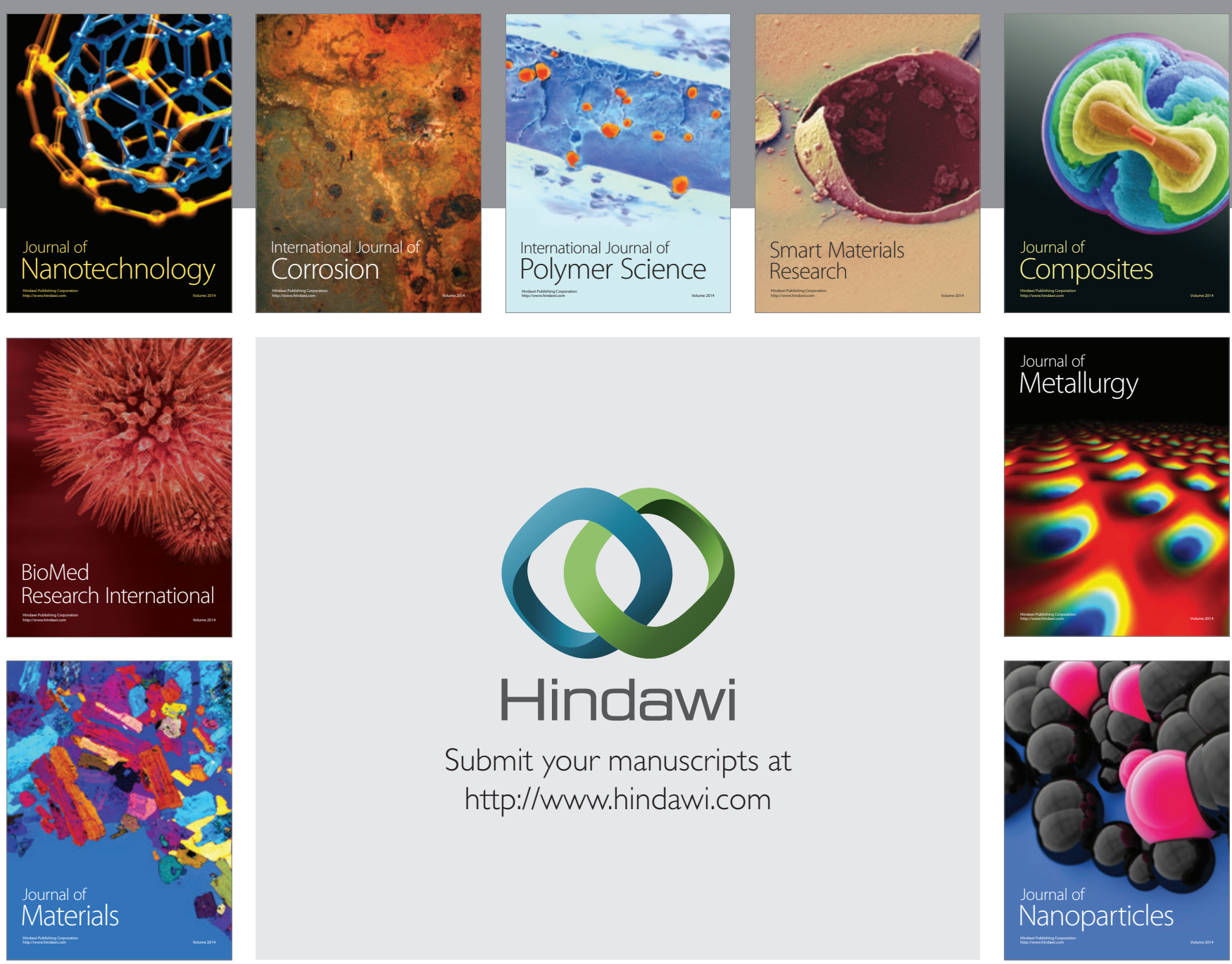

Submit your manuscripts at http://www.hindawi.com
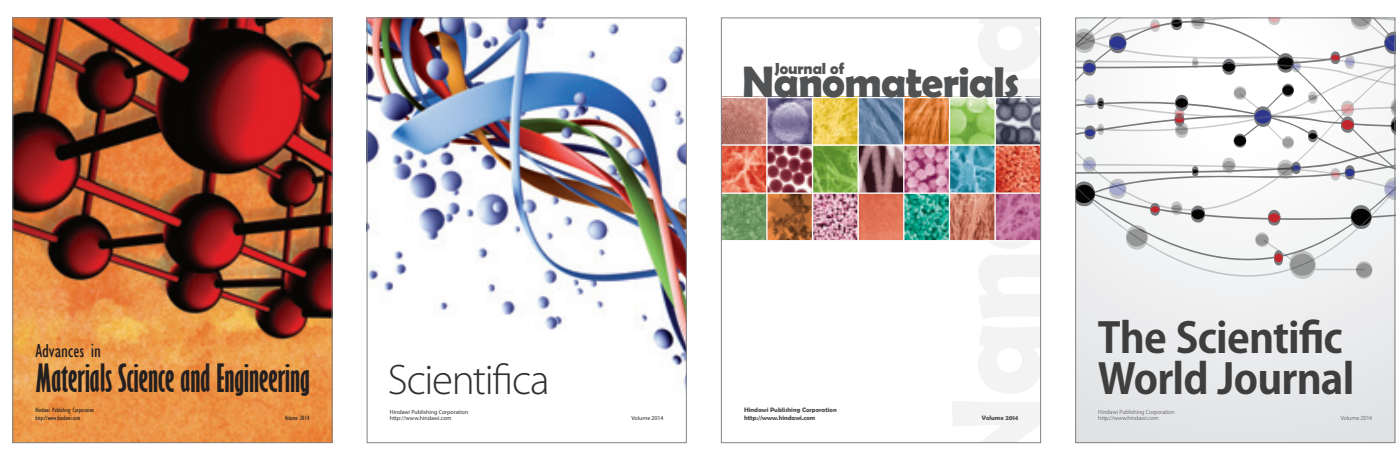

\section{The Scientific World Journal}
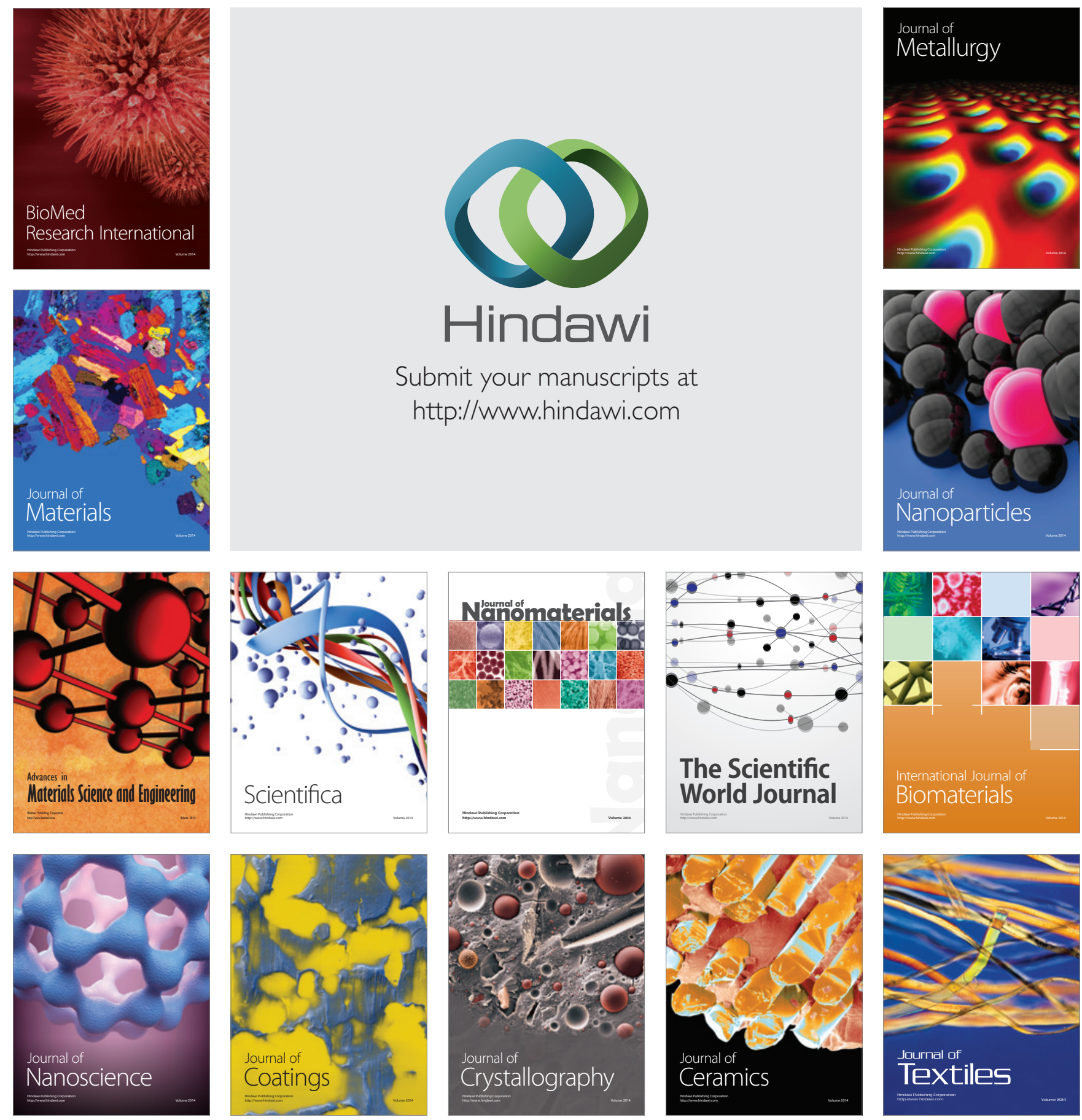